\title{
The traditional hunting on Greater Green Leafbird (Chloropsis sonnerati) in East Java: A vulnerable situation for vulnerable bird
}

\author{
Agung S. Kurnianto*1, Adityas Arifianto ${ }^{2}$, Eko Narjianto ${ }^{3}$, Anggun S. Firdaus ${ }^{2}$, Muhammad Iqbal ${ }^{4}$, and Nia Kurniawan ${ }^{2}$ \\ ${ }^{1}$ Postgraduate, Brawijaya University, Malang, Indonesia \\ ${ }^{2}$ Department of Biology, Faculty of Mathematics and Natural Sciences, Brawijaya University, Malang, Indonesia \\ ${ }^{3}$ Kelompok Pecinta Alam Purwoharjo, Banyuwangi, Indonesia. \\ ${ }^{4}$ KPB-SOS, Tanjung Api-api street km 9, Komplek P and K, Blok E1, Palembang, Indonesia.
}

\begin{abstract}
Greater Green Leafbird (GGL) Chloropsis sonnerati is one of the favorite songbird in Indonesia and live harmoniously among local people. However the increasing human needs creates a vulnerable situation, both to socio-economic and bird sustainability. This study aims to reveal the GGL traditional hunting method in two villages within the national park. In addition, this study also aims to reveal the trading plot from the initial supply to the local traders and the fluctuation of GGL population in their natural habitat. We conducted two approaches: an explorative interview on bird traders in Malang, Jember, and Banyuwangi, and a deep interview on the national park rangers, society, and bird hunters. Local people generally use two methods for GGL hunting. Pikat method, was used to catch specific birds that mostly live on trees. The other method, net method, was not widely used by the traditional hunter. Population of GGL was considered as abundant in the past, when the demand was low and the hunting activity only conducted seasonally using pulot method. The high of demand, modernization of method, and regeneration of hunters shifted the sustainable harvest into exploitation. During 2001-2003, the trend of hunting began to decline the GGL population in nature.
\end{abstract}

Keywords: traditional hunting, pikat method, net method, Greater green leafbird

Received: 02 August 2017 Revised: 22 October 2017 Accepted: 30 October 2017

\section{Introduction}

Greater Green Leafbird (GGL) Chloropsis sonnerati is hunted and traded traditionally in Indonesia. The population of these vulnerable birds was declined due to the habitat loss and hunting activities (Birdlife International 2016). Despite its threaten status, it is still one of the favorite pets in Indonesia and is traded intensively (Chng and Eaton 2015; Iqbal 2015; Jepson et al. 2011; Su 2015). In consequence, the demand is increasing and is followed by massive hunting and trading activities.

The traditional hunting becomes inseparable part of the human culture which is related to economic social (Iqbal 2015; Jepson et al. 2011; Kristianto and Jepson 2011). Most of the people hunt for economic purposes (Iqbal 2015; Jepson et al. 2011) rather than others, such as cultural activity (Cartmill 1993; Kristianto and Jepson 2011). These facts lead to the extinction, both locally and globally. The growth of human population decreases the GGL habitat. White et al. (2005) stated that most of the deforestation activities ignore the wildlife in the forest, and sadly, it happens in almost all continents. This matter extremely threatens the birds that needed a wide space and dense vegetation to support their life (Peris and Montelongo 2014). This study aimed to reveal the traditional hunting performed by local people and the trading plot from the initial supply to local traders. We also revealed the fluctuation of GGL population in their

* Corresponding Author:

Agung S. Kurnianto

Postgraduate, Brawijaya University, MT Haryono Street no 169, Malang, Indonesia

Phone: +62 812-3276-7729 Fax: +62341-580801

e-mail: agung.sih.kurnianto@gmail.com natural habitat and make an assessment to describe a trend of future population.

\section{Method}

\section{Study Location}

We performed an explorative interview on bird traders in Malang (5 wholesalers from Splendid bird market), Jember (2 wholesalers from Trunojoyo bird market), and Banyuwangi (3 wholesalers from Kalibaru) to reveal the main suppliers of GGL in East Java. This explorative interview was conducted on July-September 2014. Then, based on that collected information, we determined the research sites on 2 villages in Meru Betiri National Park, Sukamade, and Bandealit, that known as one of the good quality GGL sources in East Java, even in Indonesia.

\section{Data collection}

We interviewed the national park rangers $(n=12)$, society $(n=15)$, and hunters $(n=7)$ who have lived or worked in this field for more than 10 years. The question that asked during the interview was including the estimation of GGL population that was observed during the last 10 years, the GGL behavior, and the captured GGL. We also conducted face to face interview to reveal the price fluctuation during the last ten years. This structural qualitative research was conducted on December 2014 - September 2015. We identified the bird hunter informants using snowball method by following the local trading chain of birds and revealing the hunting activities in nature. Parcitipatory interview was conducted by following local people activities in the forest, especially during the hunting and trading to the initial trader. The intensive population survey was held in 2015. 
We projected the interview result in a complete hunting scheme, including the preparation, the material composition, and the hunting procedure.

\section{Results}

Greater Green Leafbird, that locally known as $\mathrm{Cuca}$ Ijo is a clever bird and become a symbol of the leader in the hierarchical group of birds. This species has been hunted and traded since a long time in Java, and widely in Indonesia. The informants claimed that GGL from their village is iconic among other places in East Java and infamous on entire Indonesia, called as Cuca Ijo Banyuwangi. We gathered information about two methods that generally used by local people for hunting GGL. Each of those methods had different purpose and had been used for certain condition.

Pikat method or birdlimes was used to catch specific birds that mostly live on the trees such as GGL, Bluewinged Leafbird (Chloropsis cochinchinensis), Greycheeked Bulbul (Alophoixus bres), Black-capped bulbul (Pycnonotus melanicterus), and Dark-throated Oriole (Oriolus xanthonotus). Hunters usually prepare pantek or pegs before hunting. Pegs were made from common bamboo (Dendrocalamus asper), with a length of $\pm 30 \mathrm{~cm}$ and diameter of $\pm 6 \mathrm{~cm}$. Tip of the peg was sharpened diagonally (from two sides or the same as a sword). The number of pegs varied depends on the hunters, usually hunters brought 200 pegs (or more). Hunters were also preparing pulot or glue trap from Bendo latex (Artocarpus elasticus) and rubber tree (Hevea brasiliensis). Bendo and Rubber tree were cut diagonally with a wide of $10-15 \mathrm{~cm}$. They placed the cuts of Bendo in a higher position, approximately 5-10 m, in order to avoid the disruption from national park ranger (see Figure $1 \mathrm{~A} \& \mathrm{~B}$ ). Tapping process that was conducted inside conservation area is an illegal activity. Thus, red-handed hunters will receive harsh penalties. The rubber latex was collected from the plantation near the national park by using a container made from coconut shell, Cocos nucifera. Both of latex was harvested on the next day, mixed, and stored in the bamboo (called bumbung).

Each team (consists of 2-5 hunters) had a smart bird for call bait that produce a noisy calls. This bird called as plenguk. Most hunters utilized the same species for bird bait, though other bird that sings loudly and noisily could be used. The main role of Plenguk is to attract other birds to come and perch on the glue trap. Once they stuck on the glue trap, even if it just their feathers, they would not be easily released from the trap and some of them would fall. Pikat method is usually applied at 6 am $-2 \mathrm{pm}$, though the time range depends on the location of the trap. Some hunters changed the trap location every six hours regarding to the biggest chances to catch the birds. A professional hunter could identify the trees and their location, in where the GGL mostly perched.

Hunters climbed the potential trees that were predicted to be frequently perched by GGL. Climbing process was followed by some ethnics that still be done by local people until now. They hit each peg onto potential trees on odd count (5-7 times), followed by chanting a spell. Although nowadays the spell chant was no longer used, local people still did the odd count for hitting pegs. After arriving at the suitable branch, the hunters cut some branches, and this strategy called as antrap or antrapan. Antrapan is a strategy to anticipate the adaptation behavior. Hunters chose the random branch to avoid making a regular pattern (see Figure 1C). Local people believe that GGL could observe the hunting technique that usually applied by hunters. Therefore, a group of birds that lead by a bird would try some branches before other birds perch at the branch. In this case, antrapan technique has an important role on deceiving the leader of the bird.

The hunter duty did not over after they set the trap. They started to hide and observe the traps. Hunters would collect the birds after one or more birds were trapped and after the other birds left. The captured birds were put into the bumbung and locked it by plugging sada to the hole. This method was repeated on the same or different trees until the hunters collected the desired number of GGL. Then, they reported the collected birds by marking the trees during their way back. This kind of communication was very important to avoid the repetition on the same trees by other hunters or taking other hunter's trapped birds that had not been collected. It also shown that hunting activity among hunter groups was not a competition but a big teamwork using traditional system. The communications sometimes gave positive results for other groups and replied by giving some vegetables to the first groups that found GGL and also gave a sign.

Another method, Net method, did not use widely by the hunter due to its application that only on the dry season and could not catch the specific targets. The net was large, easily visible for this illegal activity, and expensive for the majority of people. More birds were caught by using this method than pikat method. The dry season would be followed by the dry river, therefore birds would search for other rivers inside the forest. This river provided a wide space to expand the net and gave a high possibility to capture more birds.

The net wide was range from 2-3 $\mathrm{m}$ with a length of 10-15 m. It was expanded across the river and supported by two bamboos as pillars. The low part of the net was bent to catch the fallen bird after bumping the net (See Figure 1D). All those materials were left for 1 until 3 days. Some hunters would check it once a day, at 2-3 pm. The captured birds were put in a cage, covered by leaves or cloth, and hidden until the dusk. The hunters would bring it home at night and hide it for some period of times.

\section{Local Strategies Toward the Best Price}

The captured bird would undergo two processes: first, selling it to the initial supplier directly at the time; second, improving its quality by some specific treatment before selling it. The second option would be applied if the selling price is low (see figure 2). During the treatment, hunters would treat and teach the birds to eat artificial food, voer, until they could reach a higher price. During treatment process, the hunter also acted as a trainer. Recently-captured bird was placed on a quiet room, far from human and other bird's noises, and also had a low lighting. Birds on those rooms were fed by 
banana and cricket. If birds were on stress, then sometimes hunters would give sugar water as a recovery process. Banana and cricket were reduced until once per two days in order to make bird starving and accept all kind of food, including artificial food. The food-changing process started with diet composition consisted of $25 \%$ artificial food for a whole week, then multiplying it until $100 \%$ artificial food. If birds were able to eat diet consist of $100 \%$ artificial food, then it means GGL have been ready for sale.
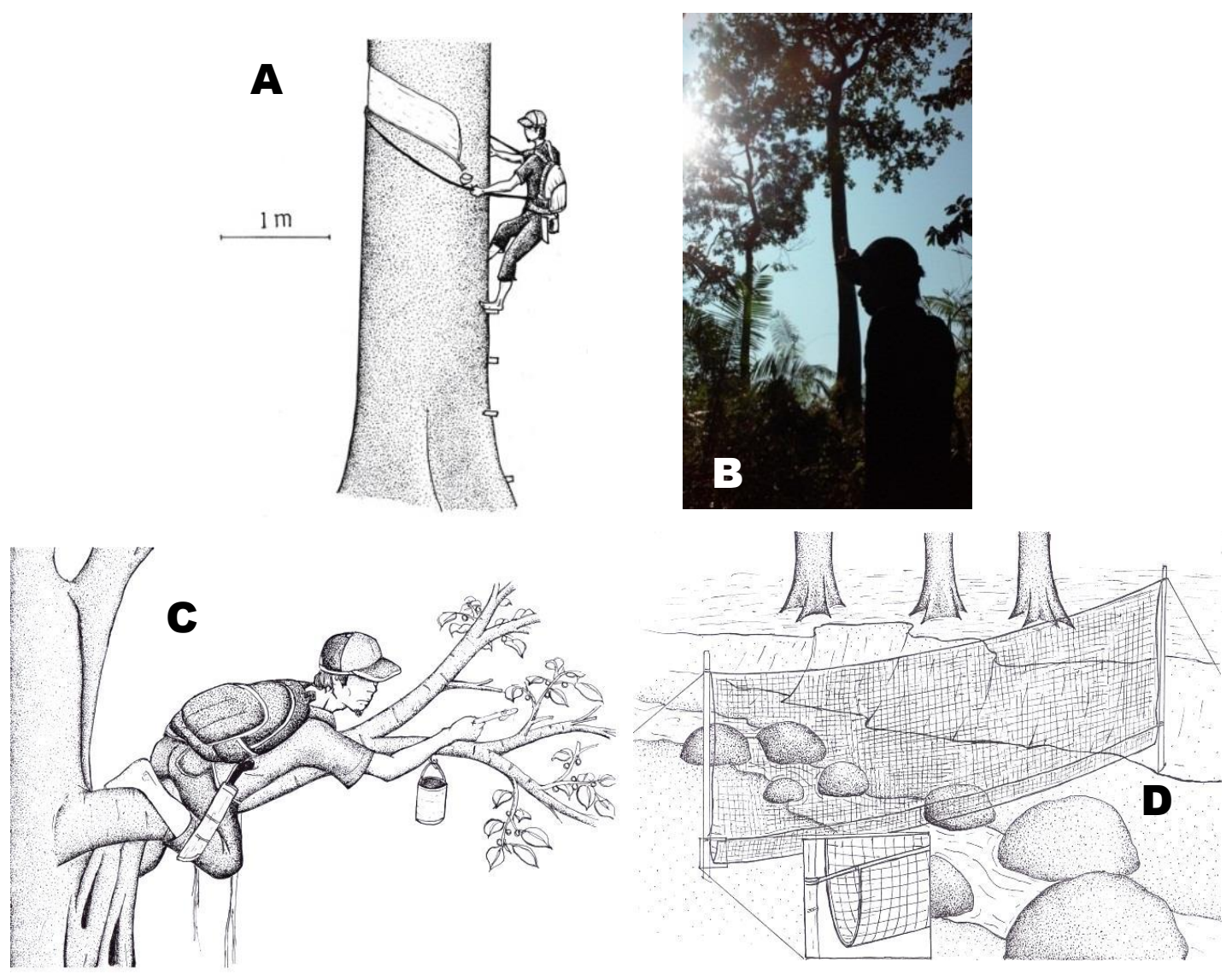

Figure 1. (A) A sketch shows how hunter work on Bendo tapping : Pantek (pegs) are plugged as the foothold, while ropes are wrapped to help them climbing; (B) a hunter shows the high estimation of Bendo; (C) Pikat Method and (D). Net Method, with corner insert.

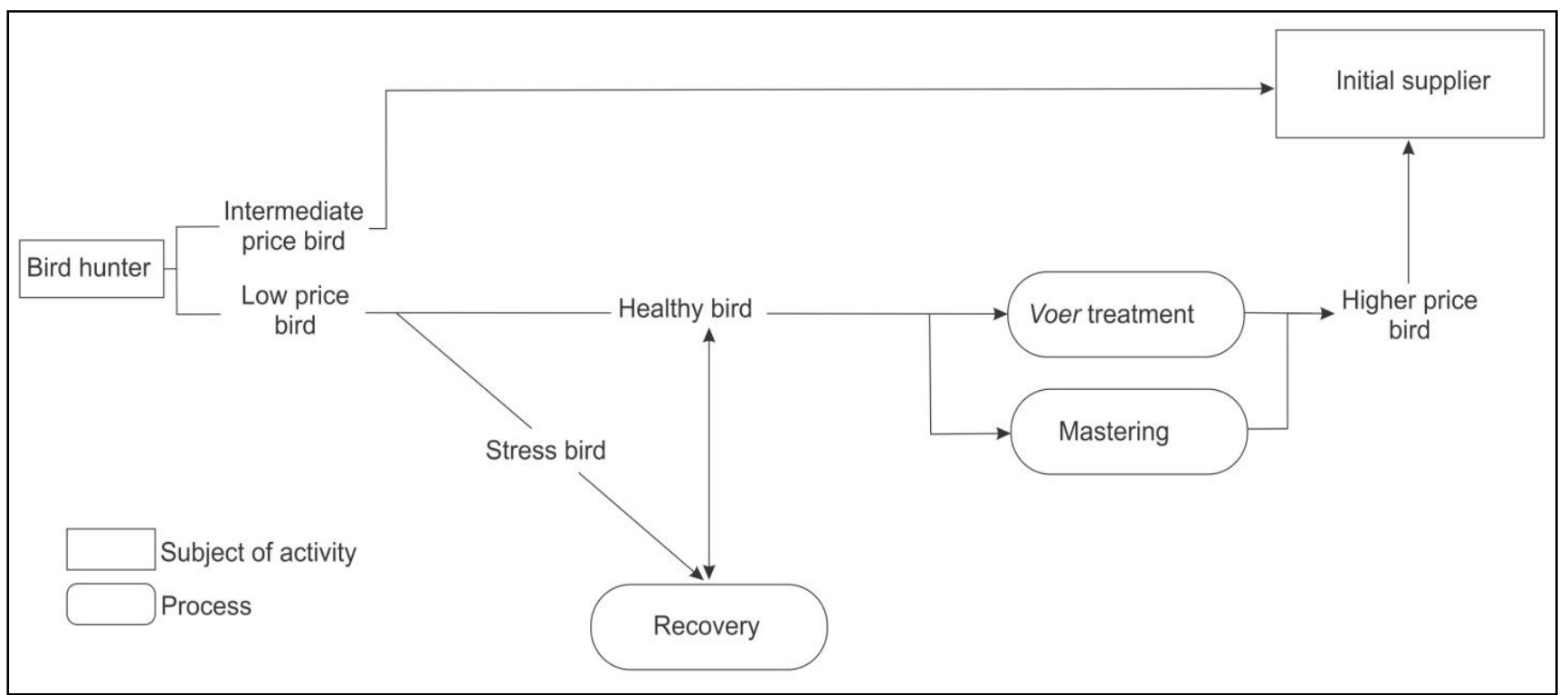

Figure 2 A schematic of GGL supply chains

The food-changing process followed by bird's voice training. Bird's song recorded, both GGL and other bird's

voices were played from dusk until morning rises. This training called mastering to teach GGL many kinds of 
songs and GGL was expected to imitate it well. Foodchanging and mastering treatment can increase the price for 2-3 times. Bird collector from city would visit hunter on the village and offer some prices for the captured birds, both trained and untrained birds. If they already reached an agreement, the collector would bring the birds by bamboo and hide it under the jacket. Local hunters avoided national park ranger observation by not taking a risk which emerges with sending the bird to buyer by themself. Nevertheless, no local hunters have ever been arrested by national park ranger.

Although the population of GGL classified as abundant, but the demand is low (see figure $3 \& 4$ ) and the hunting activity only conducted seasonally by pulot method. The hunting season was only conducted in the dry season. The rainy season also became a mating season for GGL, and it was valued by local people in the past, so they would not enter the forest at all for hunting, aside of the difficulties on entering the forest due to the forest density. They also believed that GGL will be difficult to be found on the rainy season compared to the dry season, where the juveniles population usually rose. On hunting season, each hunter harvesting GGL on a limited number, i.e 5 until 6 male bird only, which female was released back. This also affected by the demand that mostly limited on the male, so the female could regenerate in their nature. Local people that recognized this process will provide sustainability of GGL harvesting on the next season. Every local people who violating this unwritten rule will get a warning from other senior hunters. During 2001-2003, the trend of GGL population began to decline (see figure 4). Thus caused by a series factors: the increasing market demand, the increasing number of young hunter, and the emergence of net method.

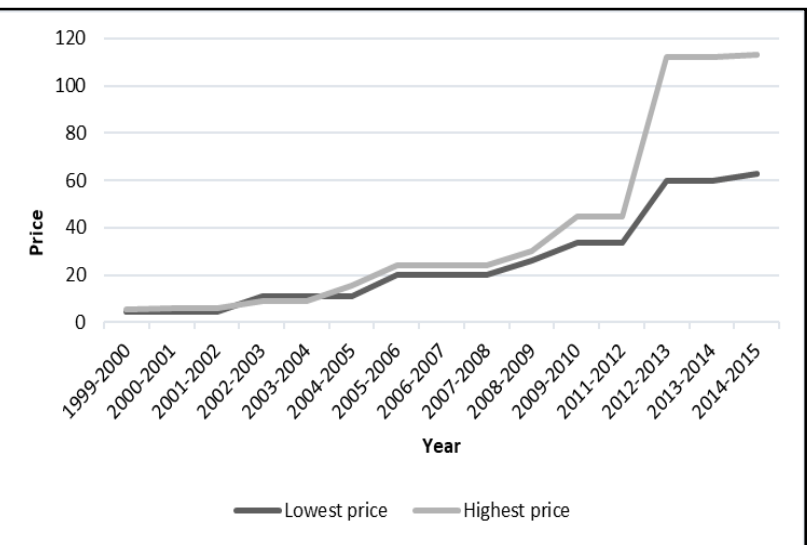

Figure 3. Comparison of reported annualy price (USD1=IDR13292 ; untransformed data) by bird hunter in face-to-face interview

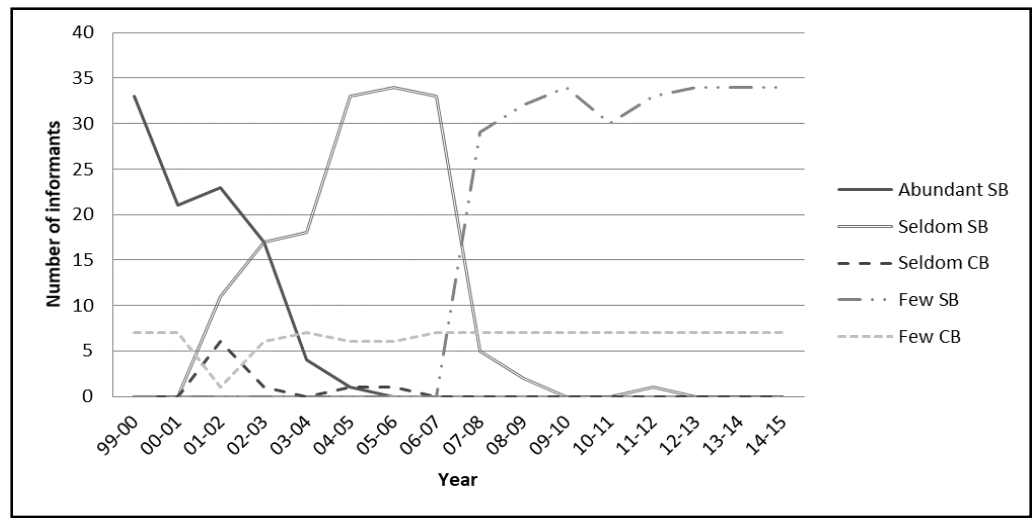

Figure 4. Graph of seen and captured bird estimation as reported. We configure the quantity counted as minimal individu by face-to-face interview. Key : Abundant (100-200), Seldom (30-99), Few (0-29), SB (Seen Bird), CB (Captured Bird),

\section{Discussion}

Sukamade and Bandealit exist since Netherlands colonial era, precisely along with the opening of plantation sector on south area of East Java, long before conservation area administratively opened in 1997. Existence of villages inside conservation area often makes friction between conservational matter and local people social economic matter. Wildlife killing activities, such as toward boars and deers, are often occurred to protect crops on the plantation. Uniquely, bird hunting as a potential secondary job became a trend to support economic needs at an economy crisis in 1999. Most of the men preferred to become a bird hunter at that time, rather than mammals hunter.

Traditional hunting couldn't be separated from the rural society, especially in Sukamade and Bandealit (Foresta et al. 2000). In other words, traditional hunting is a form of local wisdom practices that connected human and nature which created a harmony between them (Cartmill 1993). A traditional hunting resulted in a management activities and limitation on the number of captured birds (Fitzwater 1982, Kristanto and Jepson 2011). Pulot method, as traditional method, indirectly maintains the population sustainability compared to the modern hunting method that utilized modern equipment, regardless the impact on climate (Fernandes-Ferreira et al. 2012; Fitzwater 1982). The materials used in birdlimes were varied through its long historical story, such as european used Holly Bark (Ilex aquifolium), American used slippery elm (Ulmus rubra), while African used other plants, such as Loranthacae. Society on tropical area often utilizes Moraceae to form tools (Fitzwater 1982). Pulot is a method of selecting the target that will be captured. This shows that the local people gives an opportunity for the GGL to regenerate. The increasing number of birds hunter during the post-reformation era (1999) indicated the increasing of people's will on managing the forest where they lived by using their own method (Wulan et al. 2004). This also affected their boldness on hunting the GGL in the conservation area that is 'illegal' in the law perspective.

Traditional beliefs have long been spread on people that a massive hunting would reduce the number of the captured bird on the next season. This tradition shows that there was a local management provide population sustainability of GGL. The utilization process applied together with population management of wild bird would improve the economic value along with the conservation program (Kristianto and Jepson 2011). 
Net method uses a harvesting tool that targets more general bird species (not specific) and allow researcher to monitor bird population (Marques et al. 2013; Singh et al. 2016). In contrast, this methods potentially harm natural population if it is being used by hunters, because hunters will not sort their harvested bird anymore, results on opportunistic exploitation. Basically, the young generation hunter does not respect nor apply the old pulot method, they prolong the time and applied it during dry and rainy season. Because of over-hunting practices, hunters started to feel the extinction toward this species in 2013. This is confirmed by the observation of national park rangers (Kurnianto 2015). Furthermore, it affected indirectly on reducing the hunters from 64 person in 1999 to 7 person in 2015. Recently, most of hunters switch their professions, such as cultivating, herding, or moving to the city.

A traditional hunting is still conducted by some hunters in the conservation area, although it seriously breaks the rules and triggers some conflicts between the society and government (Platt 2012; Wulan et al. 2004). Regarding to this matter, the government needs to enforce the policy of environmental conservation and animal trading in order to reduce animal hunting and traditional trading ( $\mathrm{Li}$ 2007). On the other side, the government has to respect the traditional culture that has existed before the establishment of the national park (Suratri 1998). Due to the dilemma faced by the government, traditional beliefs that gives a positive impact on the conservation must be respected and developed, because it could avoid a massive exploitation (Kristianto and Jepson 2011). On the other hand, hunters were initially local people who occupy that area long before the national park itself. For generations, local people feels that the existence of forest next to village is a guaranty for their life, i.e. economic

\section{Acknowledgment}

We thank the bird trader and the kelompok pecinta alam Purwoharjo that help on collecting the qualitative data. We also thank all of the informants on field, including the national park rangers and local people.

\section{References}

Barnagaud J-Y, V. Devictor, F. Jiguet, M. Barbet-Massin, I. Le Viol, et al. 2012. Relating habitat and climatic niches in birds. PLoS ONE 7(3): e32819.

BirdLife International. 2016. Chloropsis sonnerati. The IUCN Red List of Threatened Species 2016: e.T22704950A93992403. http://dx.doi.org/10.2305/IUCN.UK.2016-3.RLTS.T22704950 A93992403.en. Downloaded on 30 June 2017.

Cartmill, A. 1993. A view to a death in the morning. Harvard University Press, Cambridge.

Chazdon, R. L. 2008. Beyond deforestation: Restoring forests and ecosystem services on degraded lands. Science 320: 1458 1460.

Chng, S. C. L., and J. A. Eaton. 2015. Snapshot of on-going trade: an inventory of birds for sale in Chatuchak Weekend market, Bangkok, Thailand. BirdingASIA 25: 24-29.

Foresta, H., Kusworo, A., Michion, G., Djatmiko, W.A., (eds.). 2000. Ketika Kebun berupa Hutan: Agroforest Khas Indonesia Sebuah Sumbangan Masyarakat. Bogor : ICRAF.

de la Peña-Domene, M., C. Martı'nez-Garza, S. Palmas-Pe'rez, E. Rivas-Alonso, and H. F. Howe. 2014. Roles of Birds and Bats in Early Tropical-Forest Restoration. PLoSONE 9(8): e104656. social aspects, and has a distinctive philosophy value (Foresta et al. 2000). This matter was truly not acceptable and became a dilemma for local people that conservational boundary suddenly appeared in 1997, resulting a limitation for their traditional activity, including GGL hunting. All this 'crime' is deceived to be ended, but local people always found a way to resist if their rights were not fulfilled. Although GGL hunting is not acceptable, but we could not deny its important roles on economic, cultural, and conservation aspects. The utilization on cultural aspects would create an innovative ways to conserve GGL, due to the important part of culture itself. Other songbirds, such as Orange-headed Thrush (Zoothera citrina), give a proof that birds can be used traditionally and also affect economic income for salak farmer in Bali. Harvesting process based on traditional management will give a bright future of Orange-headed Thrush population sustainability. The Harvesting process on juvenile from the nest will stimulate the adult birds to reproduce. It will give more benefit than taking the adult birds, resulting in juvenile death and decreasing of bird populations (Kristianto and Jepson 2011). On GGL case, those two approaches, i.e traditional management and economic value increase, will be needed to increase local people perspective toward conservation activity which could result on good economic income. Harvested bird must through the sorting process based on category of juvenile or adult and male or female birds, which too old, too young, and female birds must be released back to nature. Management process shall be done better, especially in monitoring system conducted by national park. Moreover, further study is strongly needed in order to observe and reveal the synergistic relationship between national park and local people in East Java.

Fernandes-Ferreira, H., S. V. Medonça, C. Albano, F. S. Ferreira, and R. R. N. Alves. 2012. Hunting, use and conservation of birds in Northeast Brazil. Biodiversity and Conservation 21:221-244.

Fitzwater, W. D. 1982. Bird Limes and Rat Glues - Sticky Situations Proceedings of the Tenth Vertebrate Pest Conference. University of Nebraska, Lincoln.

Iqbal, M. 2015. Looking at online bird trading in Indonesia: a case study from South Sumatra. Birdingasia 24: 132-135

Jepson, P., R. J. Ladle, and Sujatnika. 2011. Assessing market-based conservation governance approaces: A socio-economic profile of Indonesian markets for wild birds. Fauna \& Flora International, Oryx (Cambridge Journals) 45(4): 482-491.

Kristianto, I., and P. Jepson. 2011. Harvesting orange-headed thrush Zoothera citrina chicks in Bali, Indonesia: magnitude, practices, and sustainability. Fauna \& Flora International, Oryx, 45(4): 492-499.

Kurnianto, A. S. 2015. Sayap-sayap Meru Betiri: Mengenal keanekaragaman burung di Taman Nasional Meru Betiri. Balai Taman Nasional Meru Betiri, Jember.

Li, P J. 2007. Enforcing wildlife protection in China, the legislative and political solutions. China Information XXI (1): 71-107.

Marques, J. T., M. J. Ramos-Pereira, T. A. Marques, C. D. Santos, J. Santana et al. 2013. Optimizing sampling design to deal with mist-net avoidance in Amazonian Birds and Bats. PLOS ONE 8(9): e74505.

Peris, S, and T. Montelongo. 2014. Birds and small urban parks: a study in high plateau city. Turkish Journal of Zoology 38: 316-325.

Platt, S. G., K. Platt, T. Z. Naing, H. Meng, W. K. Ko, N. Lin, R. J. Tizzard, K. M. Myo, M. M. Soe, and T. R. Rainwater. 2012. Birdlime in Wester Myanmar: Preparation, use, and conservation implications for an endemic bird: research communication. Ethnobiology Letters 3: 68-75. 
Sandström, U. G., P. Angelstam, and G. Mikusinki. 2006. Ecological diversity of birds in relation to the structure of urban green space. Landscape Urban Plan 77: 39-53.

Singh, N. J., A. M. Allen, and G. Ericsson. 2016. Quantifying migration behaviour using net squared displacement approach: Clarifications and caveats. PLOS ONE 11(3): e0149594.

Su, S., P. Cassey, M. Vall-llosera, and T. M. Blackburn. 2015. Going cheap: Determinants of bird price in the Taiwanese Pet Market. PLOS ONE 10(5): e0127482.

Suratri, R., and S. Agus. 1998. Lokakarya Kepala Balai dan Kepala Unit Taman Nasional se-Indonesia. Departemen Kehutanan dan Perkebunan, Jakarta.
White, J. G., M. J. Antos, J. A. Fitzsimons, and G. C. Palmer. 2005. Non-uniform bird assemblages in urban environments: The influence of streetscape vegetation. Landsc. Urban Plan 71: 123-135.

Wulan, Y. C., Y. Yasmi, C. Purba, and E. Wollenberg. 2004. Analisa konflik Sektor Kehutanan di Indonesia. Center for International Forestry Research, Bogor 


\section{Supplementary Information}

Table 1 Attractant trees and success estimation. We configure the succes estimation by compare the number of succes and unsucces of pulot method applied

\begin{tabular}{|l|l|l|l|}
\hline Local Name & Scientific Name & Attractant & Success Estimation (\%) \\
\hline Beringin Ijo & Ficus sp & Fruits and Insects & 80 \\
\hline Beringin Putih & Ficus sp & Fruits & 70 \\
\hline Beringin Merah & Ficus sp & Fruits and Insects & 80 \\
\hline Kemlandingan & Leucaena glauca & Fruits, Flowers, and Insects & 20 \\
\hline Rotan kecil & Daemonorops sp & Flower & 10 \\
\hline
\end{tabular}

Table 2 Materials and equipments needed for traditional hunting of GGL.

\begin{tabular}{|l|l|l|}
\hline Local Name & Description & Function \\
\hline Pulot & $\begin{array}{l}\text { A mixed of Artocarpus elasticus and } \\
\text { Hevea brasiliensis latex }\end{array}$ & Pulot is an adhesive material used to stick bird's foot or feathers. \\
\hline Uthik & Big knives & $\begin{array}{l}\text { To collect pulot and make pantek/tumbuk. Traditional people always bring this knive at } \\
\text { their scabbard. Uthik also used for cutting bushes, rope, bamboo, etc. }\end{array}$ \\
\hline Pantek/tumbuk & Pegs made from bamboo & As a foothold that pierced into the tree \\
\hline Tampar & Rope & Climbing equipment \\
\hline Sada & The midrib of coconut leaf & Bumbung fastener \\
\hline Bumbung & Bamboo strips & Pulot or container for the captured bird \\
\hline Kurungan & Small bird cage & Container for the bird bait \\
\hline Plenguk & Bird bait & $\begin{array}{l}\text { As a bait to attract bird targets. The bird bait is good at singing, and usually the same } \\
\text { species with the bird targets. }\end{array}$ \\
\hline
\end{tabular}

Table 3 Symbol as communication among hunters

\begin{tabular}{|c|l|}
\hline Symbol (R) & Description \\
\hline & "Go there, I got plenty of catches" or "look at my catches" \\
\hline$\longrightarrow$ & "I've tried there, and got nothing" \\
\hline $\mathrm{R}$ & \\
\hline $\mathrm{R}$ & "This is mine, do not disturb" \\
\hline
\end{tabular}

${ }^{1}$ Symbol of hunter's name 